
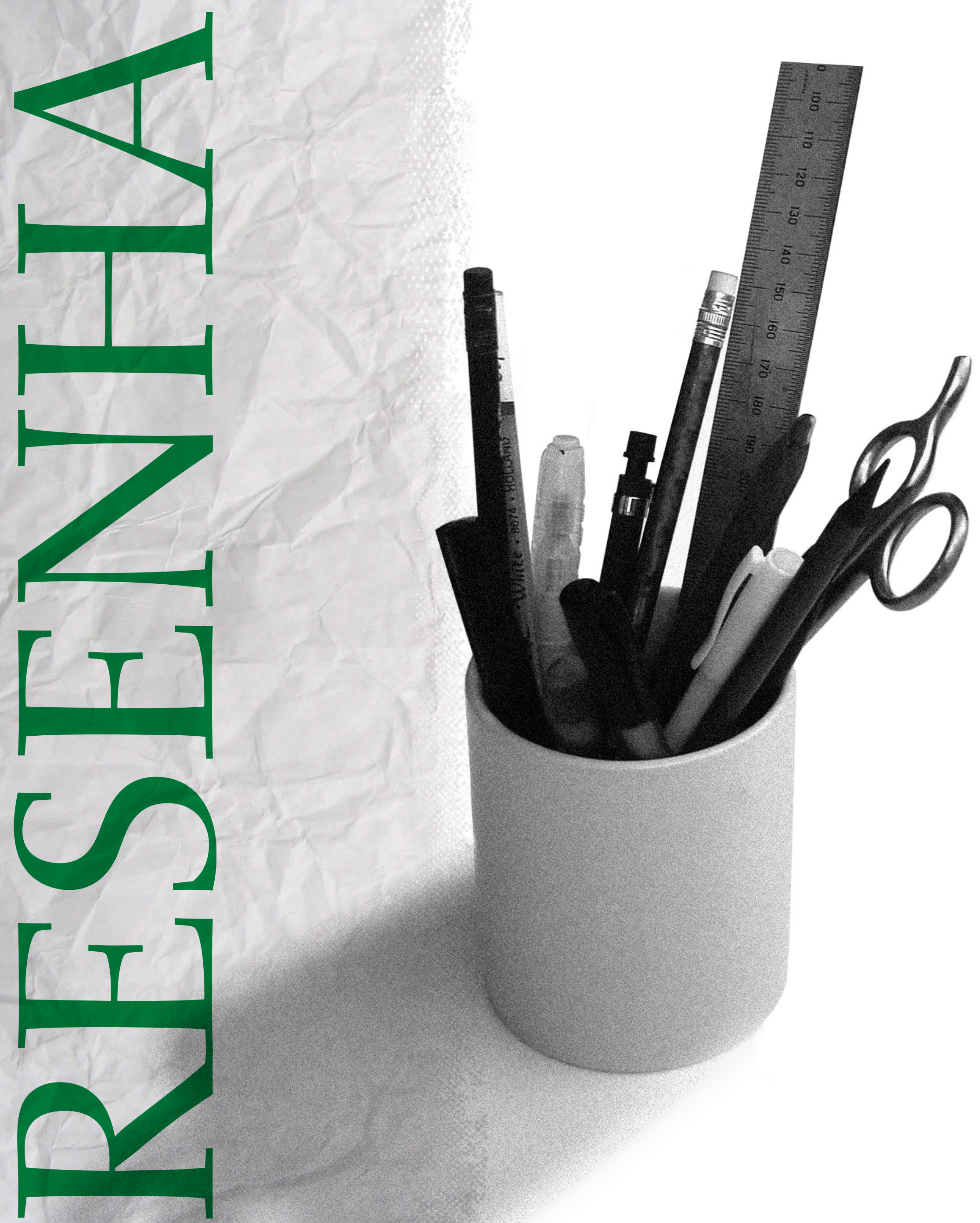


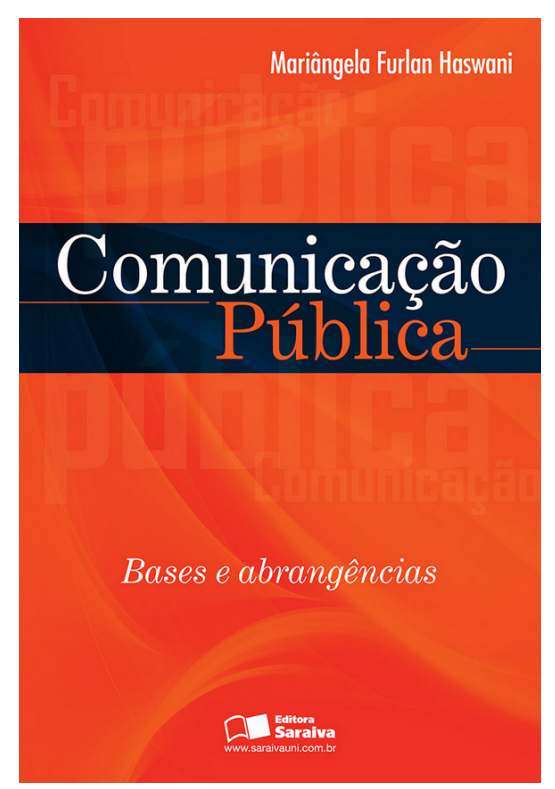

\section{Mariângela Furlan Haswani}

Comunicação pública: bases e abrangências

São Paulo

Saraiva, 2013

$183 \mathrm{p}$.

Resenhado por :

\section{Patrícia Carla Gonçalves Salvatori}

- Mestranda em Ciências da Comunicação na Escola de Comunicações e Artes da Universidade de São Paulo (ECA-USP)

- Especialista em Comunicação Empresarial e graduada em Relações Públicas pela Faculdade Cásper Libero

- Professora-colaboradora da Faculdade Cásper Libero

- psalvato@uol.com.br 


\title{
Público vs. privado: o desafio de tornar comum para toda a sociedade
}

\author{
Public versus private: the challenge of becoming \\ common for the entire society
}

\author{
Público vs. privado: el desafío de tornar \\ común para toda la sociedad
}

Q uais os limites entre público e privado? A comunicação pública se constitui como um direito de cidadania ou uma ferramenta de promoção política? A quem pertence a comunicação pública? Com base em extensa pesquisa bibliográfica e suporte nas perspectivas das ciências sociais, das ciências políticas e do direito, a obra de Mariângela Furlan Haswani responde a essas e outras questões pertinentes ao tema, por meio da análise dos fundamentos da comunicação pública em uma abordagem inédita, ampliando o escopo de estudo para além da comunicação e do marketing políticos.

O livro, fruto da tese de doutorado defendida pela autora em 2010, divide-se em seis capítulos de conteúdos distintos, mas que se complementam e entrelaçam para a formação do arcabouço dos processos comunicacionais de interesse público, inevitavelmente nos remetendo à análise do contexto sócio-político brasileiro contemporâneo.

Ao estudar um assunto de tamanha complexidade e que ainda se encontra em pleno processo de construção, se faz necessária uma releitura de conceitos como público - de conhecimento geral, passível de acesso e compreensão por toda a sociedade - e esfera pública - arena onde se discutem temas de interesse público - , este último foco também de análise e contraposição com o interesse privado, como bem detalha a autora no primeiro capítulo, "Muitas faces do público".

Em busca de um melhor entendimento do fenômeno da comunicação pública, o segundo capítulo da obra, "Estado: o público por excelência", resgata a conceituação jurídica e social de estado, democracia e o complexo universo dos direitos, que proporcionam a base para compreensão dos princípios da publicidade de Habermas - de tornar algo público - e opinião pública. Estes são apresentados no terceiro capítulo, "A publicidade estatal e a publicidade comercial". Nesse contexto, a autora discorre ainda sobre a questão da accountability, estágio mais avançado do que a transparência, no qual a divulgação das ações estatais possibilitam o controle e a intervenção da sociedade. 
Para estabelecer os fundamentos que compõem a comunicação pública, a autora aborda, de forma bastante didática, no quarto capítulo, "Comunicação: conceitos e aplicações", os esquemas de informação, comunicação, relacionamento, dialogo/debate, participação e compartilhamento. Trata-se de um processo comunicacional evolutivo que começa com a simples informação pública transmitida aos cidadãos e evolui até chegar ao patamar do compartilhamento, etapa em que a sociedade não apenas participa, mas também possui poder de deliberação e corresponsabilidade sobre a gestão e os resultados das decisões. Com isso, mais do que uma gestão participativa, termo difundido na sociedade, a autora propõe como o ápice do modelo democrático uma gestão compartilhada.

Ao discorrer sobre os meios de comunicação organizacional da atualidade, Haswani destaca a web tanto pelo impulso da transparência que gera para os entes públicos em seu relacionamento com a sociedade, bem como pelo aumento da eficiência na prestação de serviços aos cidadãos, ganho obtido por todos os setores sociais. Entretanto, há que se considerar que a tecnologia por si só não representa melhorias, uma vez que a comunicação pública depende de fatores e vontades políticas que a façam acontecer, o que vai além da implementação de modernizações tecnológicas.

Em seu quinto capítulo "Conceitos e classificações da comunicação pública", que pode ser considerado o centro nevrálgico da obra, a autora se apoia em conceituados autores italianos para classificar a comunicação pública a partir de três dimensões: se o foco está nos emissores/promotores da informação, comportando, portanto, apenas a comunicação originada por entes públicos; se o foco está na finalidade do processo comunicacional, ou seja, qualquer organização pode promover a comunicação, desde que não possua viés de utilidade econômica/comercial; e por último, se o foco se estabelece no objeto da comunicação, que por consequência deve ser de interesse público.

Em um segundo modelo classificatório acatado pela maioria dos autores estudados na obra, a divisão se dá em três aspectos: comunicação da instituição pública, comunicação política e comunicação social. A comunicação da instituição pública visa promover a imagem das instituições e garantir a compreensão de produções normativas, obrigatórias nos estados democráticos por tratar da divulgação das leis. Já a comunicação política tem por objeto temas de interesse geral, mas de caráter privado, seja dos partidos políticos ou de outras instituições, e caracteriza os cidadãos como sujeitos eleitores. A última dimensão, da comunicação social, que comporta não apenas atores estatais, mas também privados que possuem interesses públicos, subdivide-se em quatro áreas: social, de serviço, de responsabilidade social e das instituições quase-publicas. O melhor dos mundos, na visão da autora, é que as entidades públicas promovam a prática pró-ativa de todas essas modalidades conjuntamente, de forma a assegurar a transparência exigida dos estados democráticos e garantir os direitos fundamentais e sociais da população.

O sexto e último capítulo, "Outras dimensões da comunicação pública", como o próprio titulo diz, aborda aspectos alternativos como a comunicação administrativa ou de cidadania, que possui o propósito de resolver problemas de interesse geral, e a comunicação da esfera pública, 
promovida pelas organizações do terceiro setor. Na sequência, o leitor é brindado com a metáfora do "edifício de Rolando", uma nova abordagem do estudioso Stefano Rolando, que compara a comunicação pública com um edifício de sete andares, numa escala evolutiva, sendo o térreo o patamar básico da comunicação administrativa e o sexto e último andar, representado pelo gerenciamento da identidade competitiva, por meio do branding.

Em suma, Comunicação pública: bases e abrangências chega para ocupar um local de destaque na bibliografia sobre o tema, que há tempos necessitava de obras de porte e consistência teórica como esta. Como ressalta Margarida Kunsch no prefácio, trata-se de um conteúdo de extrema valia tanto para futuras pesquisas científicas como para o apoio na atuação prática dos profissionais nas esferas do estado e da sociedade. 